\title{
REFLECTIONS ON THE CURRENT ECOLOGICAL CRISIS AND REACTIONS THROUGH ART
}

\author{
Abhilasha Pandey \\ Research Scholar (JRF), \\ Dept. of Painting, \\ Kala Bhavana, Visva-Bharati University, \\ Santiniketan, \\ West Bengal.
}

DOI: https://doi.org/10.36713/epra4090

\begin{abstract}
The varied constituents of Indian society differ enormously among themselves in their access to the resources of the earth. Today, we dwell in the 'age of ecological arrogance'. Women and Nature have both undergone exploitation. This paper deliberates on the present ecological scenario giving insights from important writers. It further discusses how ecological disturbance instigated into an art practice. Giving examples, it reflects on the practices of some important contemporary ecological artists of India.
\end{abstract}

KEYWORDS: Ecology, Environment, Ecological Art, Eco-Artists

\section{INTRODUCTION}

India represents one of the most complex societies in the world. This is a society that encompasses within its ranks Stone-Age huntergatherers of the Andamans and white-collar privileged of Delhi, artisanal fisherfolk of Tamil Nadu and purse seine workers of Goa, wandering shepherds of Himachal Pradesh and roadsidedwelling populaces of Calcutta, shifting cultivators of Mizoram and sugar barons of Maharashtra, fuelwood head loaders of Kumaon and engineers drilling the Bombay high for offshore oil, textile mill owners of Coimbatore and software exporters of Bangalore. These varied constituents of Indian society indeed differ enormously among themselves in their access to the resources of the earth. (Gadgil \& Guha, 1995). We are now in the middle of what might be called an 'age of ecological arrogance' in the Indian subcontinent. In an attempt to create a mass consumer society, India, like China, is trying to ape the West, whose members can all drive their personal cars, live in their own air-conditioned houses, eat in extravagant eateries and travel to the ends of the world for their intimate holidays. (Guha, 2014).

For centuries, artists have always been enthused by the beauty and mystery of Nature and have used elements of the natural world in creative ways. Observing the present ecological crisis in India, many artists have reacted in their own ways to the deteriorating situation. Art that addresses environmental issues has now become a part of the artistic mainstream which was once an area of interest for a relatively small group of people. In contemporary art scenario, the natural world is considered not only as a source of inspiration or subject to represent creatively but also as a realm to influence directly in the public sphere. It is regarded as a sphere of action to transform and improve the environment through creative means by adopting a wide range of approaches and methods- from a passive reviewer or questioning researcher to visionary innovator to dynamic interventionist looking for social and political transformation. (Brown, 2014). This paper discusses the amalgamation of two important domains, i.e., ecology and art. It further ponders on Eco-art and discusses various artists who practice in this domain of art.

\section{A REFLECTION ON THE CONTEMPORARY ENVIRONMENTAL SCENARIO}

"There are invisible writings on the blank pages of these desolate places which tell the story of how some civilizations had for ages elaborately busied itself in preparing its own burial ground." (Chaudhury, 2012). This quotation is as relevant today as it was about a hundred years ago written by the eminent personality- Rabindranath Tagore. Even 
Mahatma Gandhi presaged that if India took the British or American model of industrialization, it 'would strip the world like locusts.' (Guha, 2014). Guha further elaborates:

"Gandhi did not glorify poverty; he knew the Indian masses needed decent education, dignified employment, secure housing, freedom from want and from the disease. Likewise, the best Indian environmentalists do not ask for a return to the past, but for nurturing of society, and economy, that meets the demands of the present without imperiling the needs of the future." (Guha, 2014)

On one hand, Gandhi talked about India as a 'village republic'. But on the other hand, people, in fact, visualize the villages are disappearing. And they really disappear in their heads and therefore the conditions are fashioned for the insulated urban system' that is associated much more to the West culturally and to China materially leaving the real India behind. Thus, the goods come from China and the ideas and concepts are derived from the West. (Jahanbegloo, 2013)

\section{ECOLOGY AND FEMINISM}

When we look at our civilization's history and we move forward to our contemporary world, we can denote that our society has constantly chosen the 'yang' over the 'yin'. It chose rational knowledge over intuitive wisdom, science over religion, competition over cooperation, exploitation of natural resources over conservation, and the list goes on. This emphasis is undoubtedly reinforced by the patriarchal system and further fortified by the dominance of sensate culture during the past three centuries. This has resulted in a deep cultural imbalance that lies at the very root of our current crisis- an imbalance in our thoughts and feelings, our values and attitudes, and our social and political structures. (Capra, 1982)

Women, who have been acknowledged with Nature throughout the ages, have both undergone exploitations synchronously. From the earliest times, Nature was seen as a kind, caring and fostering mother, but also as a wild and uncontrollable female. Her many facets were recognized with the numerous manifestations of the goddess. Under patriarchy, the benevolent image of Nature got altered into inaction and the understanding of Nature as wild and dangerous upsurge the idea that she has to be dominated and subjugated by man. Simultaneously, women were depicted as passive and subservient to men. With the escalation of Newtonian science, Nature became a machine-driven system that could be manipulated and browbeaten, in conjunction with the manipulation and exploitation of women. (Capra, 1982)

According to the renowned ecofeminist of India, Vandana Shiva argues that the epidemic of violence perpetrated on women in India is linked to both the environmental breakdown and rural impoverishment instigated by the corporate funding of the biotech research. In her book Staying Alive, she notes,

"With the violation of Nature is linked to the violation and marginalization of women, especially in the third world. Women produce and reproduce life not merely biologically, but also through their social role in providing sustenance. All ecological societies of forest-dwellers and peasants, whose life is organized on the principle of sustainability and the reproduction of life in all its richness, also embody the feminine principle." (Jahanbegloo, 2013)

Shiva also states that the patriarchal development and domineering economic measures strip women of their traditional land-use rights and disrupt the living partnership between women and Nature. Along with causing such havoc, globalization's market fundamentalism is responsible for the oppression and victimization of women, dalits, tribals, and minorities. (Jahanbegloo, 2013)

\section{THE REACTION: ECOLOGICAL ART OR ECO-ART}

The singular challenge of the current era is to respond to current environmental crises. But why through Art? Because artists possess astute communication skills that can disseminate existing environmental strategies of reform and preservation. Most importantly, art's inspirational capacity can activate the behavioural changes and policy reforms of custodial care for our planetary home. Moreover, the creative ingenuity that is the special province of art can be directed to life-sustaining problem-solving. And above all, art has long served as the conscience of a culture. (Weintraub, 2012)

Ecological art emanates under the umbrella term 'Environmental Art', where artists who are anxious regarding the imbalance and degradation of the ecosystem create art. The current crisis of climate change has given added impetus and urgency to many of these artists' practice. These artists draw on wide interdisciplinary knowledge that pleases heart and mind. It addresses the interconnections between various aspects of the environment, social, ecological, cultural and historical notions. Eco-art rouses dialogue and instigates respect and reverence towards Nature contributing to the socio-cultural transformations. (Wallen, 2012). Mostly, eco-artist work in collaboration with others and undertake complex projects with specialists from other disciplines.

One can find that in many cases, unlike the scientist, the artist's role is not to provide conclusive answers. Simply posing questions in the mind of the 
spectators is often enough and the motive of the work. Artists have the power to engage with the local communities and can gather extensive support that science alone can seldom do. Their practices instigate awareness, dialogue, and action which can bring about real change, deliberately or unintentionally. Thus, whether to a few or to many, it has a lasting benefit. (Brown, 2014) turtles on the beach of Kochi, this work emphasizes the idea of coasts as a mass-grave of our natural resources. This site-specific performance installation forces us to contemplate on the ecological issues and the atrocities we are bombarding on our planet. It also talks about the overuse of resources by contemporary society without being thoughtful about the future. By recreating the turtles that accidentally and mythically nested on the beaches of Kochi, this captivating work

\section{Artists}

1. Ravi Agarwal

Environmental artist and photographer Ravi Agarwal created a public art project in Delhi in 2014 called Project Y (Public. Art. Outreach). Its curatorial ideas were to re-imagine and transform the overriding narrative of the river Yamuna as being 'dirty' to it being 'beautiful', and to 'reproduce' it as an ecological public space accessible to all. This project was also a proposal for an ecologically sustainable Delhi. There were a number of eco-ethical questions inscribed within the project, such as- should the river be left to flow unregulated, irrespective of its utility; in what way should we thinks of rivers, ecosystems, technology and urban spaces'; what will happen if economy is replaced by ecology; and will the question of

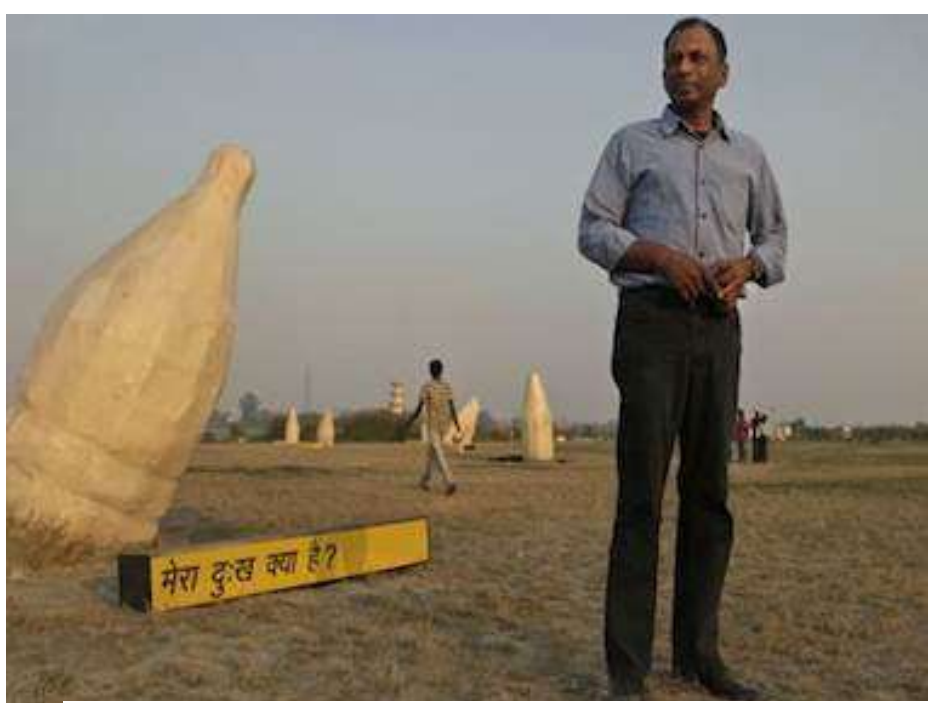

Figure 1: Site View of Project Y

by Rathod entails very important messages entwined within it regarding the balance and harmony of our ecosystem. The slow decomposition of these organic natural materials acts as a metaphor in the work- the time we have in hand to conserve our ecosystem. did in 2011 was "Mistaken case of Turtles". Using locally available natural organic materials to recreate

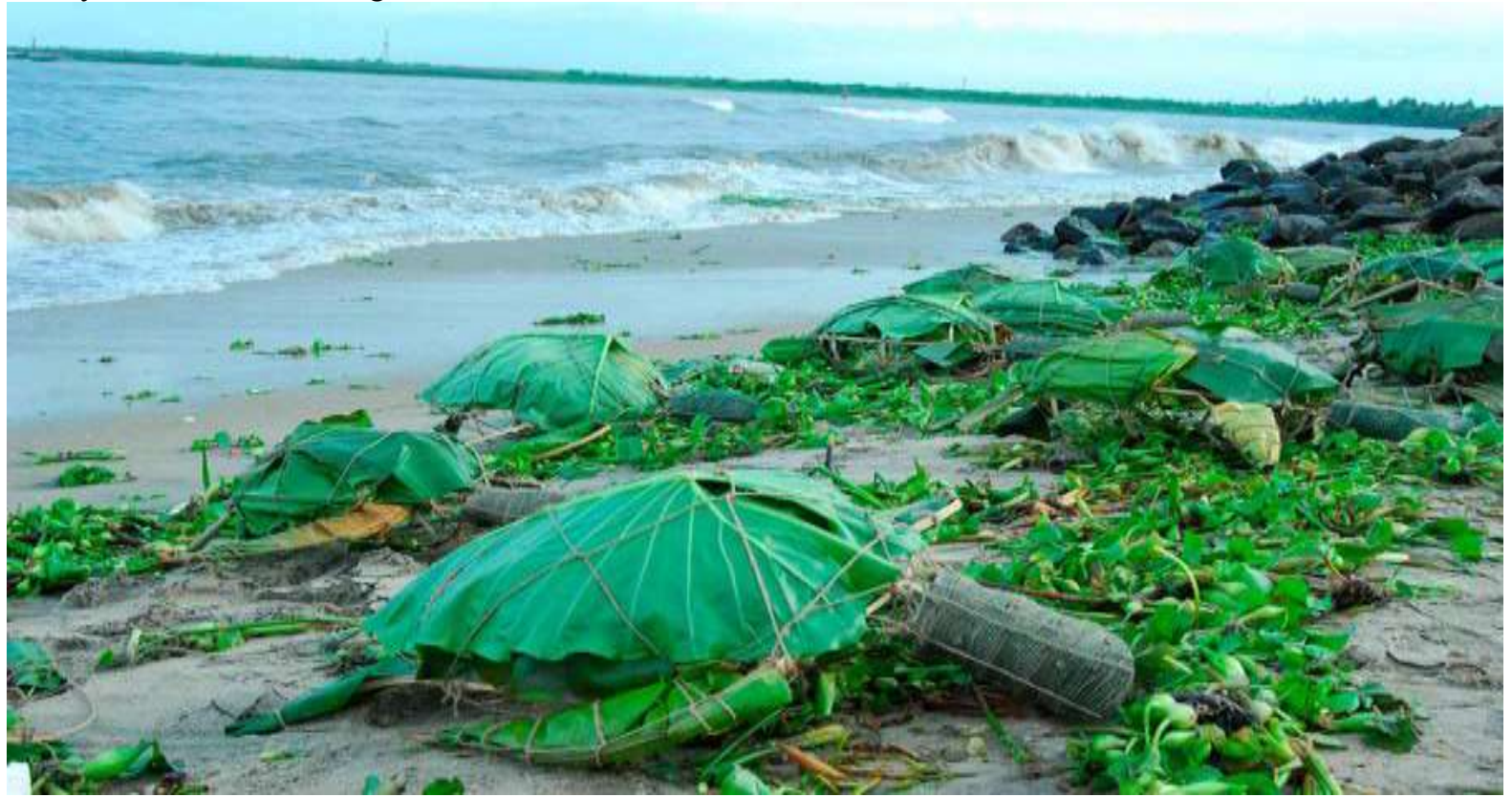

Figure 2: “Mistaken case of Turtles”, Medium : Banana leaf, Bamboo, Jute thread, Organic red pigment colour; Size : life size of Olive 


\section{Vivan Sundaram}

A well-known artist Vivan Sundaram created 'Flotage' at the public art festival called '48degree Celsius Public. Art. Ecology' in 2008. He used ten thousand plastic bottles (a global symbol of consumption and waste) and formed a raft which he set afloat on the Yamuna River. This assemblage of plastic bottles was displayed on the site and posed questions in the minds of spectators regarding consumerism, probable future 'water wars' and other water-related issues. It remarked satirically on the abundant global commercial drinking water which is one of the culprits of polluting the waterways. (48 Degrees Celsius, 2008)

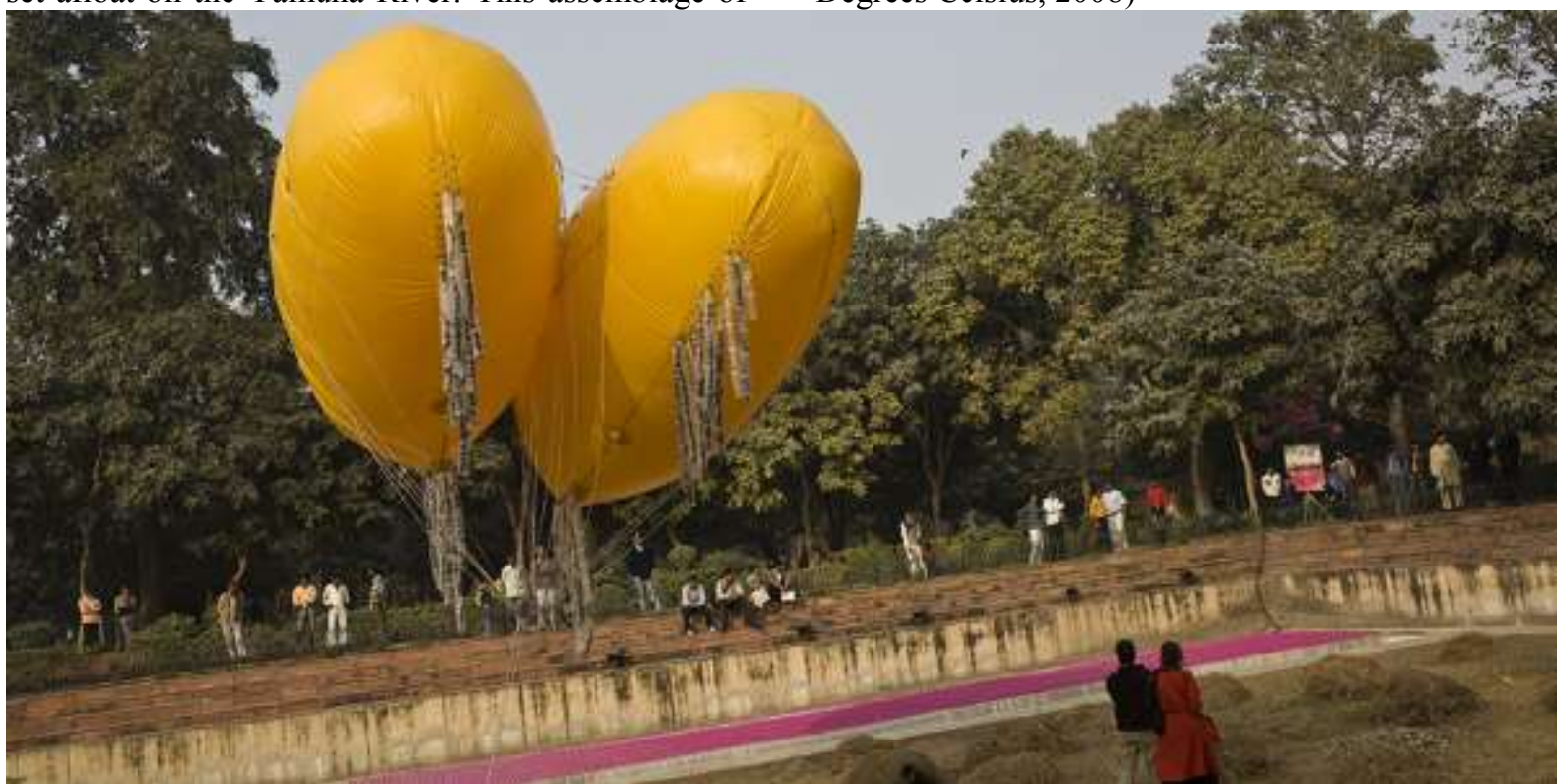

Figure 3: Flotage by Vivan Sundaram

\section{Shweta Bhattad}

A very zealous artist- Shweta Bhattad generates awareness among the public through performance art. Performances in the public domain raise cognizance regarding various social and environmental issues. Tate organisation defines it as "Artworks that are created through actions performed by the artist or other participants, which may be live or recorded, spontaneous or scripted." This art practice also comes in the canopy of ecological art. She drew focus on farmers' issues by doing many performances almost every year after her post-graduation.

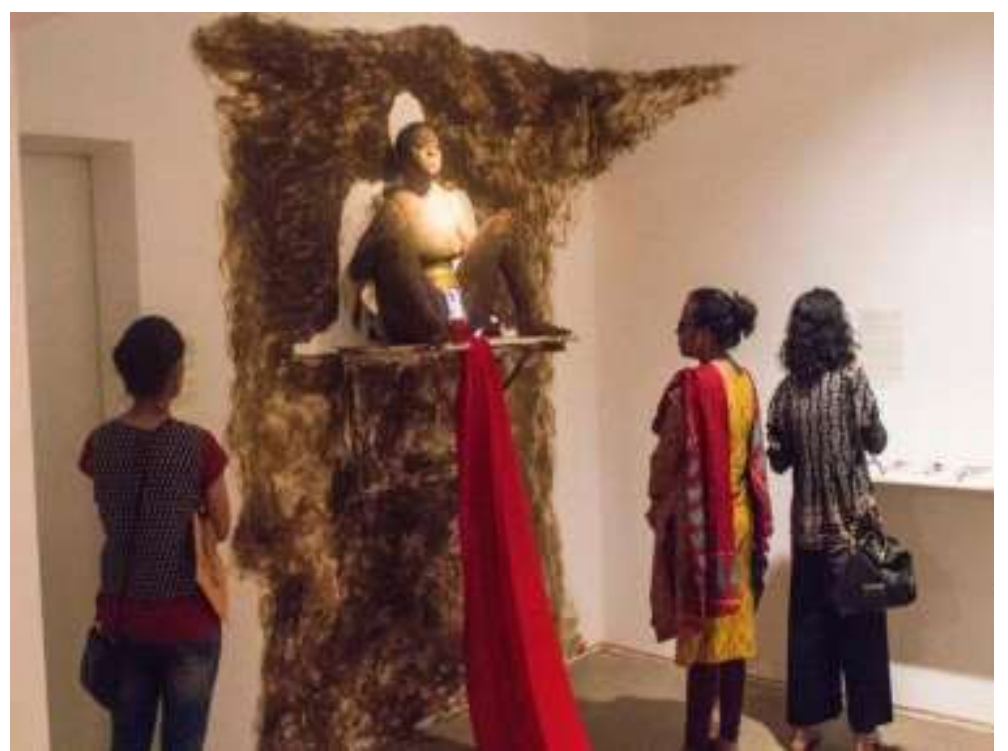

Figure 4: 'Barren Orgasm' performance by Shweta draws focus on Farmer's issues 

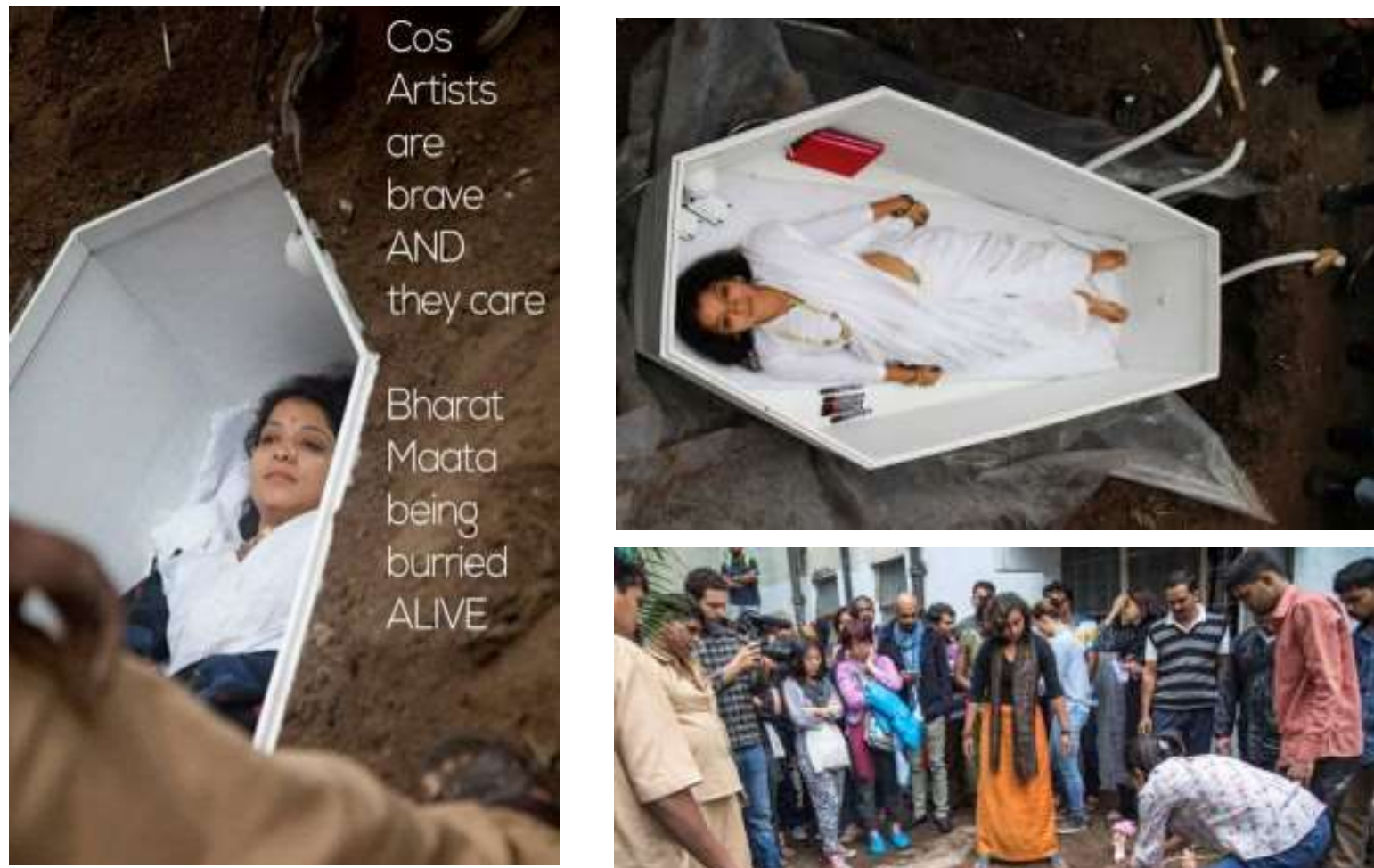

Figure 5, 6, 7: Artist Shweta literally buried herself for farmers' cause.

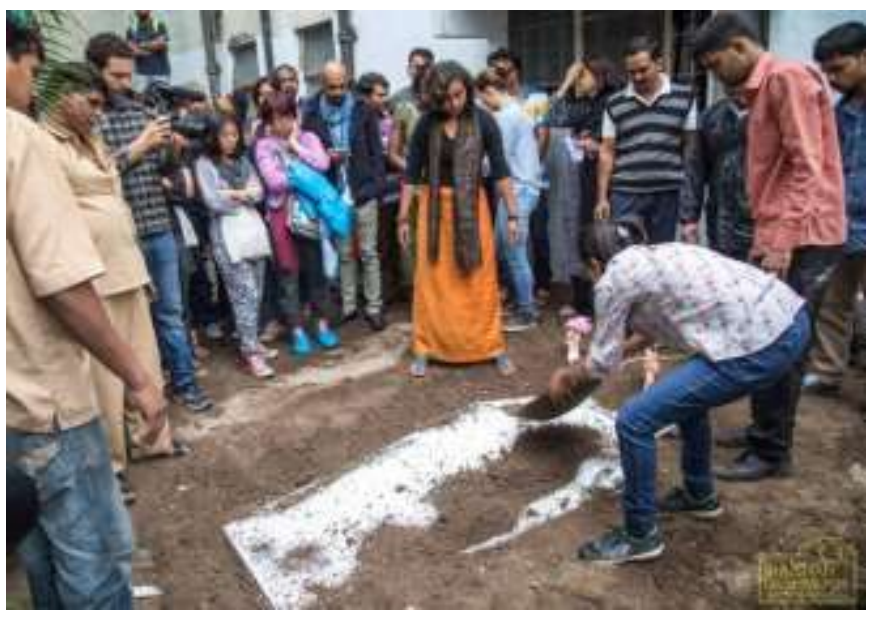

\section{CONCLUSION}

"A child born today might swim in a stream free of toxic waste, but he won't ever see a natural stream. If the waves crash up against the beach, eroding dunes and destroying homes, it is not the power of Mother Nature. It is the awesome power of Mother Nature as altered by the awesome power of man, who has overpowered in a century the processes that have been slowly evolving and changing of their own accord since the earth was born. We didn't create this world but we are busily de-creating it." (Mckibben, 2006)

In our civilization, we have altered our environment to such a degree that we have lost touch with our biological and ecological base more than any other culture or any other civilization in the past. On one hand, this departure establishes itself in a prominent discrepancy between the development of intellectual power, scientific knowledge, and technological skills, and on the other, of wisdom, spirituality, and ethics. since the Greeks embarked on the scientific venture in the 6th BC. Scientific and technological knowledge has grown enormously. nonetheless, there has been hardly any advancement in the conduct of social affairs. during these 25 centuries, (Capra, 1982).

Ecologically concerned art practices can play a significant role by encouraging dialogue and offering visions of desirable sustainable futures, both informed by and informing an "environmental value system," or "ecological ethic," as well as the concept of ecological justice. (Wallen, 2012). Ecopractitioners' actions are environmentally impactful and advantageous, they recognize humankind's' moral duties to respond to the human-caused ecological crises of the present-day by enacting environmental reform. Their work nurtures collaboration between humans and the land, which fosters a sense of ownership and responsibility within people to restore their own landscapes. Their practices and methods prove to be great examples of social and ecological rejuvenation in the public domain. 


\section{REFERENCES}

1. 48 DEGREES CELSIUS. (2008), Retrieved from http://eco-publicart.org/48-degrees-celsius/

2. Agarwal, R. (2014), "Re-imaging the River", In Seminar 657. p.p: 27

3. Brown, A. (2014), "Art and Ecology Now. Thames and Hudson.

4. Capra, F. (1982), The Turning Point, Harper Collins.

5. Choudhury, $P$ (2012), Tagore, the Father of Environmentalism, Sagnik Books.

6. Guha, M. G. (1995), Ecology and Equity, Penguin Books.

7. Guha, R. (2014), Environmentalism: A Global History, Penguin Books.

8. Jahanbegloo, R. (2013), Talking Environment, Oxford University Press.

9. Mckibben, B. (2006), The End of Nature, Random House.

10. PERFORMANCE ART (n.d.), Retrieved from https://www.tate.org.uk/art/artterms/p/performance-art

11. Wallen, R. (2012), Ecological Art: A Call for Visionary Intervention in A Time of Crisis, In Leonardo, 45(3), p.p: 234-242

12. Weintraub, L. (2012), To Life! - Eco Art in Pursuit of a Sustainable Planet, University of California Press. 